\title{
Do Pará à Amazônia: a região como problema e promessa da nação a partir do discurso parlamentar nortista $\left(1840\right.$ - 1867) ${ }^{1}$
}

\section{From Pará to the Amazon: the region as a nation's problem and promise from the Northern parliamentary speech (1840 - 1867)}

Roberg Januário dos Santos*

\begin{abstract}
Resumo
Este artigo é uma contribuição à história regional do Brasil e à história da Amazônia, com o objetivo de analisar como temas provinciais foram transformados em questões regionais e nacionais no discurso parlamentar nortista, buscando examinar nesse processo como foi ocorrendo uma transição na forma de conceber o espaço por parte dos representantes políticos do Norte às margens do rio Amazonas. A leitura da documentação e da bibliografia, permitem-nos compreender que após 1840 foi sendo projetada pela classe política nortista uma tentativa de superação de certo sentimento de distância e abandono em relação ao Governo Central do Brasil. Nesse contexto, nota-se um processo de ampliação do espaço de reinvindicações políticas, notadamente do Pará à região amazônica. Portanto, os parlamentares buscaram concomitantemente elevar as questões complexas do âmbito provincial (navegação e imigração) ao domínio regional e nacional, denotando a dupla tarefa para criar as condições de emergência da região amazônica e inseri-la na Nação.
\end{abstract}

Palavras-chave: Agentes políticos. Pará. Região amazônica. Nação.

\begin{abstract}
This article is a contribution to the regional history of Brazil and to the history of the Amazon, with the aim of analyzing how provincial themes were transformed into regional and national issues in the northern parliamentary discourse, seeking to examine in this process how a transition has occurred in the way of conceiving the space by the political representatives of the North
\end{abstract}

\footnotetext{
${ }^{1}$ Este artigo é parte integrante de uma pesquisa mais ampla acerca da constituição da região amazônica, desenvolvida no Programa de Pós-Graduação em História da Universidade Federal do Pará. O presente trabalho foi realizado com apoio da Coordenação de Aperfeiçoamento de Pessoal de Nível Superior - Brasil (CAPES) - Código de Financiamento 001.

*Doutorando pelo Programa de Pós-Graduação em História pela Universidade Federal do Pará (UFPA). Professor do curso de História da Universidade Federal do Sul e Sudeste do Pará (Unifesspa). E-mail: roberg.assu@hotmail.com
} 
on the banks of the Amazon River. The reading of documents and bibliography allows us to understand that after 1840 an attempt was made by the northern political class to overcome a certain feeling of distance and abandonment in relation to the Central Government of Brazil. In this context, there is a process of expanding the space for political claims, notably from Pará to the Amazon region. Therefore, parliamentarians seek to simultaneously raise complex issues from the provincial level (navigation and immigration) to the regional and national domain, denoting a double task to create emergency conditions for the Amazon region and insert it into the Nation.

Keywords: Political agents. Pará. Amazon region. Nation.

\section{Introdução}

"A questão do Amazonas não élocal, não équestão chamada de província, éuma questão
nacional que interessa a todo Império".
"Éuma das nossas primeiras necessidades concorrer para o desenvolvimento das Regiões
Amazônicas povoando às margens do grande rio"."

No pronunciamento à Câmara dos Deputados do Brasil, de 21 de março de 1864, o Deputado paraense Domingos Antônio Raiol, futuro Barão do Guajará, argumentava perante as autoridades imperiais presentes naquela oportunidade sobre a necessidade de abertura da navegação internacional do rio Amazonas para o desenvolvimento da região amazônica, visto que tal realização representaria o progresso da região, especialmente por permitir o desenvolvimento do comércio e a chegada de imigrantes estrangeiros, o que acarretaria a importação de capitais, trabalho, braços e indústrias.

Os temas relacionados à navegação e ao povoamento dessa parte do Brasil foram os principais a serem proferidos pelas suas elites políticas, bem como serviram para iniciar a definição de certo recorte regional a partir da semântica conexa à região amazônica, de modo que essa parte do país começou a se descolar da grande área Norte do Brasil que abarcava, até então, várias outras províncias do que hoje se chama região Nordeste. Assim, o objetivo deste texto é analisar como temas provinciais foram transformados em questões

${ }^{2}$ RAIOL, Domingos Antônio. Abertura do Amazonas: Extratos dos debates no Parlamento brasileiro acerca do projeto de lei sobre a abertura do Rio Amazonas à navegação e ao comércio do mundo (1867). Pará: Typografia do Jornal do Amazonas, 1867. p. 11.

${ }^{3}$ Ibidem, p. x., p. 21. 
regionais e nacionais no discurso parlamentar nortista, para compreender como foi ocorrendo a transição na forma de conceber o espaço por parte dos representantes políticos do Norte amazônico. Esse objetivo nos conduz a uma questão nodal do trabalho: quais os temas e argumentos para a ampliação do espaço paraense com vistas à ideia de região no período estudado?

Este estudo contribui com a historiografia amazônica e brasileira naquilo que diz respeito às discussões sobre a emergência da ideia de região amazônica e examina o papel da classe política desta parte do país no processo de inserção da região à Nação. $\mathrm{O}$ artigo colabora decisivamente para a compreensão acerca do momento em que os representantes políticos dessa área do país ampliaram o espaço de atuação política e passaram a fazer menção não só ao Pará, mas também ao Vale do Amazonas e a região amazônica, o que denota que a região não existe desde sempre, é uma construção, possuindo uma história de elaboração. Nestes termos, esse texto complementa o campo de estudos e a historiografia acerca da constituição da região amazônica, o que é justificado em face desse campo carecer de um estudo que investigue a emergência da região nesse período e por meio da ação dos agentes políticos.

Não estamos trabalhando neste estudo a perspectiva de analisar a constituição da Amazônia a contar do processo de construção da unidade do Estado Nacional como um Império, ${ }^{4}$ nosso foco é outro: compreender a construção da região amazônica com base na própria região, de seus temas e agentes políticos, visto que, além das preocupações do Estado imperial com a integração da Nação por meio das suas regiões de fronteira e da busca de certa unidade política e administrativa, nossos estudos e fontes apontam o papel fundamental dos agentes nortistas (políticos, intelectuais) na elaboração da região mediante diálogos, circulação e intercâmbios de práticas e ideias.

Teoricamente, o trabalho analisa a região amazônica por intermédio do conceito de espaço posicional, concebendo a dimensão espacial como condição de tomada de posição, lugar por meio do qual se almeja alcançar determinado objetivo. Tal conforme é salientado por Albuquerque Júnior, "o espaço posicional é aquele que implica uma preparação para o ataque ou para a defesa, espaço de luta, espaço que emerge da luta, que é riscado, esquadrinhado, demarcado, sulcado pelas contendas de todos os tipos que atravessam o social". ${ }^{5}$

\footnotetext{
${ }^{4}$ Sobre a constituição da Amazônia mediante a formação do Estado brasileiro como um Império ver o trabalho: NUNES, Francivaldo Alves. A Amazônia e a formação do Estado Imperial no Brasil: unidade do território e expansão de domínio. Almanack. Guarulhos, n.3, p.54-65, 1ํㅗㄹestre de 2012.

${ }^{5}$ ALBUQUERQUE JÚNIOR, Durval Muniz de. Nos destinos de fronteira: história, espaços e identidade regional. Recife: Bagaço, 2008. p. 72.
} 
O espaço será discutido por meio do conceito de região, no que lhe concerne a sua construção mediante um processo de disputas, interações e complementaridades com o nacional e até o mundial. Por isso, adota-se como visão geral ligada à região amazônica o conceito de regionalismo. Nesse ponto, a nossa interpretação vai ao encontro da concepção teórica de regionalismo elaborada por Maria Silva Leoni. Para essa autora, "o regionalismo representa um esforço por criar uma consciência e uma ideologia política dentro e em nome da região". ${ }^{6}$ Ou seja, ao invés da regionalização que pressupõe a integração e o controle da região pelo Estado Nacional, o regionalismo é justamente um movimento no sentido contrário, geralmente é um discurso que visa criar as condições políticas de importância, diferenciação e reconhecimento do espaço regional perante a Nação.

As fontes principais selecionadas para este texto são os pronunciamentos de parlamentares nortistas registrados nos Anais do Parlamento brasileiro, a exemplo de João Batista de Figueiredo Tenreiro Aranha, Herculano Ferreira Penna, Bernardo de Sousa Franco, Tito Franco de Almeida e Domingos Antônio Raiol, bem como Aureliano Cândido Tavares Bastos. Além dos Anais do Parlamento, outras fontes complementam a escrita desse artigo: matérias de jornais, relatórios de viajantes, relatório de Presidente de Província e coletâneas de discursos parlamentares.

$\mathrm{O}$ artigo foi dividido em quatro partes. Na primeira, apresentamos o tema, os objetivos, as ideias norteadoras do trabalho, as fontes consultadas e os aspectos teóricos. Logo em seguida, na segunda parte, discutiremos o contexto histórico em que, diante de certo distanciamento não só geográfico, mas também político, foi gestado algum sentimento de abandono da região às margens do rio Amazonas, o que desencadeou o disparo de uma série de discursos das elites paraenses acerca da necessidade de atenção com a Província e região por parte do Governo Central. Adiante, na terceira parte, discutiremos como os agentes políticos nortistas transformaram e elevaram questões provinciais ao nível regional e nacional, especialmente após 1840, como foi o caso das demandas ligadas à navegação e ao povoamento. Por fim, mas não menos importante, concluiremos o que se traduz como quarta parte do artigo.

${ }^{6}$ LEONI, María Silvia. Historia y región: la historia regional de cara al siglo XXI. Folia Historica del Nordeste. № 24, Resistencia, Chaco, Diciembre 2015. IIGHI - IH- CONICET/UNNE - p. 171. 


\section{O Pará: de Estado separado do Brasil ao discurso da Província abandonada}

As razões pelas quais se gestaram sentimentos de distanciamento e até de separatismo em relação ao Brasil, por parte da sociedade do Norte às margens do rio Amazonas podem ser buscadas ainda nos tempos da América Portuguesa quando essa área constituiu primeiro o Estado do Maranhão e Grão-Pará (1621), e depois o Estado do Grão-Pará e Maranhão, desta feita, sediado em Belém e subordinado diretamente à Coroa Portuguesa desde 1751 até as décadas iniciais do século XIX. Esse espaço foi formado separado do Brasil, constituído por populações indígenas, negras e ribeirinhas, bem como pela presença de missionários, marcado pela forte presença de portugueses e relações comerciais com franceses, ingleses e até holandeses, ganhando expressão ao final do século XVIII com a praça comercial de Belém, quando o porto da cidade era um entreposto com diversos circuitos comerciais interligados ao exterior e algumas partes do interior do Brasil. ${ }^{7}$

Richard Graham evidencia que a transferência da Corte de Lisboa para o Rio de Janeiro acarretou significativa presença e proximidade dos homens do rei e do centro do poder com Minas Gerais e São Paulo, enquanto os líderes do Maranhão e do Pará, que outrora foram beneficiados pela proximidade com Lisboa, perceberam o aumento considerável no tempo e na distância em relação à sede do poder nos trópicos. Logo, naqueles tempos, maranhenses e paraenses já se sentiam prejudicados com o afastamento e, conforme o autor, as mudanças operadas pelo poder central acabaram por gerar contraposições fazendo surgir certos sentimentos de interesses locais. ${ }^{8}$ Essa situação demonstra que a diferenciação entre o Norte e o Sul do Brasil tem suas origens em tempos bem recuados da história brasileira e que perpassa o momento de 1808 .

Além do que, do ponto de vista político, a relação do Pará com os centros de poder por boa parte do século XIX parece ter sido marcada por distanciamentos, o que possibilitou as condições favoráveis para a principal tônica do discurso político de seus representantes, a saber: a falta de atenção do Governo Central com as demandas desse espaço. Antes mesmo de estar subordinado ao Governo a começar no Rio de Janeiro, os paraenses já se queixavam perante a Corte Portuguesa, como assim o fez um estudante de direito oriundo do Pará em Lisboa, Felipe Alberto Patroni Martins Maciel

\footnotetext{
${ }^{7}$ LOPES, Siméia de Nazaré. A praça comercial de Belém: negociantes e circuitos mercantis (1790 - 1808). In: Novos olhares sobre a Amazônia Colonial / organização Rafael Chambouleyron, José Alves de Souza Junior. Belém, PA: Paka-Tatu, 2016.
}

${ }^{8}$ GRAHAM, Richard. 1997. Clientelismo e Política no Brasil do Século XIX. Rio de Janeiro: Editora da UFRJ, 1997. 
Parente, nos tempos da chamada Revolução Constitucionalista de Portugal, ${ }^{9}$ quando imbuído de um projeto político para sua terra natal conseguiu galgar certa representação entre as elites portuguesas no Pará e atuando como uma espécie de representante da Província em terras lusas conseguiu ser ouvido por D. João VI, em 1821, retratando o não atendimento dos pleitos paraenses naquela Corte: "Seiscentas vezes tenho reclamado providências para que de uma vez se derrogue o montão de males que oprimem a Província do Pará!”. ${ }^{10}$

$O$ processo de independência do Brasil teve no Grão-Pará um capítulo de resistência, visto haver fortes interesses da elite econômica e política paraense na manutenção dos vínculos com Portugal, pois esse último ainda era um indispensável mercado para os produtos locais. Logo, aderir ou não à Independência via Rio de Janeiro não dizia respeito a sentimentos patrióticos, mas sim a um complexo jogo de interesses econômicos e políticos. ${ }^{11}$ De acordo com Domingos Antônio Raiol, político e consagrado historiador paraense do século XIX, em especial do período entre 1821 e 1835: “Começava o ano de 1823 e, apesar de ter sido já proclamada a independência ao Sul do Império, ainda as províncias do Norte permaneciam debaixo da dominação portuguesa". ${ }^{12}$

Para Roberto Arruda, a situação de distância que o Pará possuía dos centros de Poder durante a colônia não mudou com a independência do Brasil, ponto pelo qual recorre ao debate político já na primeira legislatura do Parlamento brasileiro no início do Império e observa que os representantes paraenses não tinham conseguido aprovar projetos, assim como tais parlamentares demonstravam que "[...] a administração do Império não tinha mudado em nada a sua postura em relação ao Pará e o Maranhão que continuavam a ser lembrados apenas quando era necessário despachar degredados [...]". ${ }^{13}$

O distanciamento e certa visão bárbara sobre o Pará foram reforçados com a Cabanagem (1835 -1840), uma revolta que por seu perfil popular (índios, negros, mestiços) foi vista pelas autoridades do Sul do Brasil como

\footnotetext{
${ }^{9}$ Um levante que buscava fortalecer o reino a partir da Corte em Lisboa, em 1820.

${ }^{10}$ PARENTE, Felipe Alberto Patroni Martins Maciel. Discurso. In: CRUZ, Ernesto. História do Pará. $1^{\circledR}$ volume. Coleção Amazônica. Belém: Universidade Federal do Pará, 1963. p. 159.

${ }^{11}$ SOUZA JUNIOR, José Alves de: Semeando vento, colhendo tempestade: o processo de adesão do Pará à Independência. In: SARGES Maria de Nazaré; RICCI Magda Maria de Oliveira. Os Oitocentos na Amazônia: política, trabalho e cultura. Belém: Açaí, 2013.

${ }^{12}$ RAIOL, Domingos Antônio. Motins Políticos ou História dos Principais Acontecimentos Políticos na Província do Pará desde o ano de 1821 até 1835. Vol.1. Belém: Coleção Amazônica, Série José Veríssimo, Universidade Federal do Pará, 1970. p. 26.

${ }^{13}$ MACHADO, André Roberto de Arruda. Redesenhando Caminhos. O papel dos representantes do GrãoPará na primeira legislatura do Império do Brasil (1826 -1829). Almanack Braziliense. São Paulo, n¹0, p. 75-97, nov. 2009. p. 97.
} 
revolta de "gentalhas" e ameaçadora à pátria. Os liberais do Rio de Janeiro, inclusive, chegaram a atribuir que o Pará pertencia à América hispânica e não ao Brasil..$^{14} \mathrm{O}$ ministro da Justiça, em 1840, Paulino José Soares de Sousa considerava que as manifestações no Pará se caracterizavam pela barbaridade e não figuravam entre crimes políticos, ponderando ainda que, além do Pará, o "volcão revolucionário do Maranhão derramou sobre Piauhy uma torrente de facinorosos ávidos de sangue, e de pilhagem". ${ }^{15}$

Os representantes paraenses no Parlamento nacional, após a Cabanagem, buscaram evidenciar em seus discursos a ideia de um espaço que carecia de atenção eminente do Governo Central, desde a alegação de sua importância para a Nação, oportunidade em que a Província era vista e dita como rica, mas impedida de prosperar pela falta de apoio governamental. Arthur Reis compreendeu esse momento como uma tentativa de soerguimento do Pará e territórios circunvizinhos com base nas articulações entre os representantes paraenses que pretendiam o esquecimento das diferenças para que não ocorresse nenhum "[...] incidente que permitisse uma direção perigosa às coisas regionais" 16 .

Um dos principais nomes e representante do Pará nesse momento da vida política provincial foi o Deputado paraense Bernardo de Sousa Franco, ele que em 27 de maio de 1840 realizou um discurso após a sua primeira passagem pela Presidência da Província do Pará retornando o tema do abandono da Província, desta feita do ponto de vista militar, reivindicando que essas forças só fossem dispensadas em momento vindouro, pois dizia: "Eu olho para o futuro em que o Pará pode ser governado de outra maneira, isto é, quando principiar a colonização, quando se estabelecer por vapor do Amazonas, quando a população toda se fôr entregando ao trabalho". ${ }^{17}$

Sousa Franco, além de se pronunciar acerca do desprezo que o Pará sofria na área militar, especialmente com a falta de oficiais e promoções das tropas, reverberava em seu discurso ainda as pautas que passaram a constar nos discursos das elites amazônicas durante o Segundo Reinado, ou seja: colonização, navegação a vapor, trabalho e fronteiras. A respeito do último ponto citado, Sousa Franco ressaltava em seu discurso a importância do Pará

\footnotetext{
${ }^{14}$ CARVALHO. José Murilo de. A vida Política. In: A Construção Nacional 1830-1889, Rio de Janeiro: Objetiva, 2012.

${ }^{15}$ Relatórios do Ministro da Justiça, 1840, Paulino José Soares de Sousa. p. 9.

${ }^{16}$ REIS, Arthur Cezar Ferreira. Síntese da História do Pará. Amazônia Edições Culturais Ltda. Belém, Manaus, Guanabara, 1972. p. 112.
}

${ }^{17}$ Annaes do Parlamento Brasileiro. Sessão de 27 de maio de 1840. pp. 500 - 502. 
e região para a segurança das fronteiras da Nação..$^{18}$ Os discursos de Souza Franco figuravam como marcos da postura discursiva que passou a postular o Grão-Pará como possuidor de problemas nacionais, principalmente quanto aos assuntos sobre migração e navegação. Entretanto, no horizonte de expectativa, o mesmo espaço ganhava ares de promissão no discurso parlamentar.

Em 11 de maio de 1840, Bernardo de Sousa Franco realizou um pronunciamento na Câmara e elencou que a desordem na Província - uma referência à Cabanagem -, além do atraso provincial, era resultado da dispersão da população. Com o intuito de superar o problema da dispersão, o Deputado discursava produzindo a imagem paraense da opulência na perspectiva de criar as condições para atrair investimentos para o Pará, ao dizer que "a província do Pará talvez seja a mais fértil do Brasil; foi descoberta pouco depois das outras, seus recursos são imensos, seus habitantes não são em geral mais ignorantes que os das outras províncias [...]". ${ }^{19}$ Sousa Franco pode ser considerado um dos iniciadores do discurso da opulência paraense, tema presente na maioria dos discursos dos agentes políticos desse espaço durante praticamente todo o Segundo Reinado. Além da defesa da imagem do homem paraense, o discurso da opulência foi uma estratégia de algumas províncias que buscavam atrair recursos, capitais e imigração.

Sousa Franco, mesmo ainda pertencendo ao Partido Conservador, discutia na Câmara dos Deputados pautas provinciais, postura mais ligada aos liberais, de modo que na sessão de 4 de junho de 1840 discorria acerca de um projeto referente às eleições e à questão da representação política das províncias no Parlamento, propondo-se a tratar da sua Província natal, argumentando acerca da necessidade de se discutir e modificar a referida representação política provincial, pois, segundo ele, o Pará era prejudicado nesta questão, visto que diante da sua população e economia, a baixa deputação que possuía era algo desproporcional. A questão do número de representantes paraenses no Parlamento foi motivo de uma longa queixa da classe política dessa parte do Brasil.

Após sua fase como membro do Partido Conservador, em 1850, o Deputado Sousa Franco já pertencia aos quadros do Partido Liberal e se pronunciava na Câmara em 5 de fevereiro desse mesmo ano. Em seu discurso, protestava contra o recrutamento militar no Pará por conta da redução do número de homens nessa área do país, o que já permite percebermos a preocupação com mão de obra, entre outras questões importantes:

\footnotetext{
${ }^{18}$ Idem, p. $\mathrm{x}$.

${ }^{19}$ Annaes do Parlamento Brasileiro. Sessão de 11 de maio de 1840.
} 
O Pará é uma província imensa, majestosa e de um futuro que deve ensoberbecer a todos os brasileiros. É no território do Pará que corre as águas desse majestoso rio que há de algum tempo ser o veículo da maior parte do Império. É nas terras do Pará por onde corre as águas desse majestoso rio, por onde hão de descer ao oceano a maior parte dos produtos da maior parte das províncias. O Amazonas é um rio que há de dar nome ao Império. É preciso que tratemos melhor aquela província. ${ }^{20}$

O Deputado paraense alça sua Província à condição de majestosa e imensa, há uma nítida associação entre o tamanho do território e a projeção de importância do Pará, um espaço projetado no discurso como futura artéria central do Brasil, corredor da produção nacional e pretendente a nomear o Império brasileiro, um espaço da promissão. Observa-se uma tentativa clara de engrandecimento paraense, uma atitude de demarcação de lugar, de elevação de sua condição no conjunto da Nação à época. Naquele período, o Pará ainda sentia os primeiros ventos do crescimento econômico da borracha e tentava se reabilitar dos tempos da Cabanagem. Sendo assim, o engrandecimento da Província representa certa vontade de alargamento do espaço, o que aventamos como uma pré-condição para o regional.

\section{Do Pará à Amazônia: a navegação e a imigração transformadas em problemas e promessas regionais e nacionais}

O contexto histórico que criou as condições de uma certa reação política, por parte dos paraenses, em relação ao Sul e ao Governo Central coincide justamente com o Segundo Reinado, iniciado em 1840, momento em que a for-

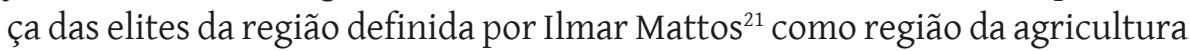
mercantil-escravista aumentou, especialmente após o Regresso Conservador. ${ }^{22}$ É importante considerar que a chamada direção do grupo Saquarema, da corrente política conservadora fluminense, comandou o Governo Central entre 1848 a 1852 e exerceu influência poderosa no Governo até a crise do Gabinete de 1868. Com isso, cabe salientar que a geografia do poder neste período delineou-se para que as províncias do Sul assumissem considerável peso político na direção do Governo, ladeado por políticos baianos e pernambucanos do Norte. Neste cenário, o Norte às margens do rio Amazonas se sentia desprivilegiado e desassistido pelo Império, bem como se ressentia

\footnotetext{
${ }^{20}$ FRANCO, Bernardo de Sousa. Discursos pronunciados na Câmara dos Deputados. Sessões de 1850, 9ำ legislatura. Rio de Janeiro: Typografia do Correio Mercantil, 1850. p. 39.

${ }^{21}$ MATTOS, Ilmar Rohloff de. O Tempo Saquarema. 5. ed. São. Paulo: Editora Hucitec, 2017.

${ }^{22}$ Movimento de antirreformas conservadoras da década de 1840 que enfraqueceu as reformas liberais, especialmente a do Ato Institucional de 1834 que concedia maior autonomia às províncias brasileiras.
} 
por não compor os quadros da construção do Estado Nacional, com poucos representantes nas esferas do poder no Brasil.

O campo econômico pode ser um bom parâmetro para cotejarmos a regionalização do Brasil no século XIX, uma vez que com as atividades produtivas e suas respectivas províncias se pode conhecer melhor a acentuação da diferença regional na segunda metade do século XIX. Richard Graham defende a ideia de que no século XIX uma força que provocava divisões era o regionalismo. Assim, considera que esse movimento fazia com que os sujeitos sentissem forte apelo ao lugar, geralmente marcado pela força das economias de cada região ao definir zonas distintas de relações políticas. ${ }^{23}$ A rivalidade entre as zonas produtivas trazia problemas ao sistema político central, inclusive, para Graham sendo o responsável por solapar o Império.

Os principais produtos agrícolas exportados pelo Brasil entre $1840 \mathrm{e}$ 1870 eram: café, açúcar, algodão, couros e peles, fumo e borracha. Sobre a arrecadação, o preço do café em relação ao açúcar e ao algodão, por exemplo, era bem mais elevado em contos de reis, entre 1860 e 1870. Assim, nota-se uma curva acentuada para cima do café e um decréscimo dos outros dois produtos, visto que enquanto o primeiro atingia cerca de 190,000 toneladas, o segundo só alcançava em torno de 60,000 toneladas. ${ }^{24}$ Essa situação no mundo da economia prenunciava a acentuação da diferença regional entre o Norte agrário (açúcar e algodão) e o Sul cafeeiro. Godoy profere que, com base no cenário econômico, social e político do Segundo Reinado, as classes dominantes das províncias, como Pernambuco e Paraíba, buscaram seu posicionamento no espaço, pois diante da perda do peso econômico ocorreu a tentativa de fortalecimento quanto aos interesses da região concorrente, notadamente o Sul, o que se traduz na produção da ideia política de Norte. ${ }^{25}$

A regionalização do Norte agrário se fortaleceu desde 1877. Albuquerque Júnior menciona que a seca foi transformada no principal problema político do Norte, hoje Nordeste. $\mathrm{O}$ autor demonstra que as elites dominantes do espaço encontraram na seca o principal argumento do atraso da região e conduziram a questão com vistas à superação das perdas decorrentes de um momento de crise vivido no Norte, sobretudo, derivado do declínio das exportações

\footnotetext{
${ }^{23}$ GRAHAM, Richard. op. cit., p. $x$.

${ }^{24}$ COUTINHO, João Martins da Silva. Curvas das quantidades do café, açúcar e algodão exportados pelo Brasil (1838 - 1887). (Manuscrito). 1p. Localizado em: Acervo João Martins da Silva Coutinho, Museu Paraense Emilio Goeldi. Belém/PA.

${ }^{25}$ SILVEIRA, Rosa Maria Godoy. O Regionalismo Nordestino: Existência e Consciência de desigualdade regional (Fac-Similiar). - João Pessoa: Editora Universitária da UFPB, 2009.
} 
do açúcar e do algodão, do rebaixamento do poder das elites políticas no cenário nacional e o descontentamento das camadas sociais com o processo de transição para a economia capitalista. ${ }^{26}$

Foi justamente no final da década de 1870 que ocorreu a cristalização da regionalização brasileira entre o Norte e o Sul, bem como aconteceu a consolidação do Norte agrário sob a liderança pernambucana, especialmente a partir de 1878 com a realização do Congresso Agrícola do Norte, sem a presença do Pará, do Amazonas e do Maranhão. Neste mesmo ano, também decorreu o Congresso Agrícola do Sul, no Rio de Janeiro, com as províncias sulistas. 0 Pará e o Amazonas ainda caminhavam paulatinamente no aprimoramento do discurso amazônico com um diferencial na economia, pois o extrativismo os distanciou dos blocos regionais agrícolas. Por isso, o espaço às margens do rio Amazonas começava a se descolar do que era a grande região Norte que abrangia a área entre a Bahia e o Amazonas, levando em conta que as demandas e os problemas do Norte agrário e do Norte amazônico não eram os mesmos, embora a crítica ao Sul partisse de ambos os espaços.

No Norte amazônico, observamos aproximações e distanciamentos com o caso do Norte agrário, ao passo que, ao contrário deste último, a economia do primeiro espaço começou a crescer após 1852 quando a extração e venda da goma elástica foi notabilizada como o principal ramo comercial. Contudo, o referido espaço também passou a viver certa crise em razão da mão de obra - as lutas entre populares e forças armadas governamentais durante a Cabanagem resultaram na morte de parte da população da região - e do abastecimento de alimentos, sendo que os habitantes nela existentes, em grande medida, passaram a lidar com a extração da borracha fazendo com que as autoridades políticas reforçassem os discursos acerca da necessidade da agricultura.

Além disso, as elites políticas amazônicas enfatizavam a ideia de uma população rarefeita nesta parte do país e que seu povoamento deveria vir de fora, especialmente para compor a força de trabalho. Acreditava-se que a resolução para o problema do povoamento estava na introdução de imigrantes estrangeiros, também percebido pela ideia de que ofereceriam exemplo prático, técnico, moral e disciplinar à população da região. ${ }^{27} \mathrm{~A}$ Cabanagem

\footnotetext{
${ }^{26}$ ALBUQUERQUE JUNIOR, Durval Muniz. Falas de astúcia e de angústia: a seca no imaginário nordestino: de problema a solução: (1877-1922). 1988. 435 f. Dissertação (mestrado) - Universidade Estadual de Campinas, Instituto de Filosofia e Ciências Humanas, Campinas, SP. Disponível em: <http://www.repositorio.unicamp. br/handle/REPOSIP/279220>. Acesso em: 10 mar. 2020.

${ }^{27}$ Sobre as propostas de imigração e o povoamento do Grão-Pará na visão de seus governantes ver: QUEIROZ, Jonas Marçal de. A Administração provincial do Grão-Pará e as propostas de imigração, colonização e
} 
possibilitou que uma grande parte dos negros e índios que trabalhavam em fazendas fugissem do domínio senhorial, constituindo uma população nômade e vivendo da subsistência. Com isso, logo ocorreu a desorganização das obrigações coloniais, o que explica, em partes, o discurso da necessidade de imigração estrangeira para suprir a mão de obra que não se tinha mais e era tida como insubordinada. ${ }^{28}$ O Presidente da província do Pará em 1853 , Joaquim da Cunha, em seu pronunciamento à Assembleia Provincial produzia a imagem dos africanos e índios como "braços" de segunda ordem, na sua visão, incapazes de alavancarem o desenvolvimento da Província:

[...] Quanto a fertilidade do solo, ela será inútil sem a agricultura, isto é, sem os braços necessários para o seu desenvolvimento, pouco se pode esperar do constrangido africano, e menos ainda do indolente indígena, que de nada precisa e só lança mão dos recursos oferecidos pela natureza, quando é aguilhoado por urgente necessidade. Resta apelar para o braço do colono europeu. ${ }^{29}$

Diante desse cenário, as elites paraenses faziam o cálculo de que a navegação estrangeira no curso do rio Amazonas, do mesmo modo que transportaria mercadorias traria imigrantes. Por isso, a ampla defesa pela navegação a vapor. Para Biggs e Burke, os navios a vapor encurtaram as distâncias entre os continentes e permitiram o descolamento de milhões de imigrantes, especialmente na rota da Europa para a América. As viagens transatlânticas passaram a ocorrer após 1839, sendo que em 1864 a Inglaterra atingiu seu apogeu na construção desses navios. Ademais, as embarcações a vapor conectariam a região à civilização, sobretudo por um processo de comunicação. Biggs e Burke reforçam que "as ferrovias e navios transportavam não somente pessoas e mercadorias entre zonas de tempo, mas também cartas - um modo indispensável de comunicação, tanto nacional quanto internacional". ${ }^{30}$

O movimento comercial provocado pela economia da goma elástica foi determinante para que o Pará assumisse uma posição regional no cenário brasileiro e nortista. Mesmo com um percentual de produção da borracha bem

povoamento do Vale Amazônico (1875 - 1899). In: COELHO, Mauro Cezar; GOMES, Flávio dos Santos; QUEIROZ, Jonas Marçal de. [et al.]. Meandros da História: trabalho e poder no Pará e Maranhão, séculos XVIII e XIX. Belém: UNAMAZ, 2005.

${ }^{28}$ WEINSTEIN, Barbara. Antes da Expansão. In: A Borracha na Amazônia: expansão e decadência, 1850-1920. São Paulo, Hucitec/Edusp, 1993.

${ }^{29}$ Fala que o Exm ${ }^{\circ}$ Dr. José Joaquim da Cunha, presidente deste Província, dirigiu à Assembleia Legislativa Provincial, na abertura da mesma Assembleia, no dia 15 de agosto de 1853. Pará: Typografia dos Santos \& Filhos, 1853.

${ }^{30}$ BRIGGS, Asa.; BURKE, Peter. Uma História Social da Mídia: de Gutenberg a Internet. Rio de Janeiro: Jorge Zahar Editor, 2006. p. 134. 
abaixo em relação ao percentual de café produzido pelas províncias do Sul, o Pará, principal centro produtor e exportador da goma elástica até 1870 no Norte do país, ascendia a certa projeção no cenário nacional, pois de 1.424. 970 toneladas em 1851 foram alcançadas 4,779,411 toneladas em 1869. ${ }^{31}$

Além disso, a historiadora Bárbara Weinstein, incorrendo na naturalização da Amazônia - como se ela fosse desde sempre - acabou, sem ter essa intenção, por resumir o que de fato aconteceu em relação à região na década de 1850 com a economia da borracha, quando afirmou que "a Amazônia emergia, afinal, do status de região economicamente atrasada que tinha desde 1823, quando declara sua independência de Portugal". ${ }^{32}$ Ou seja, a Amazônia teve seus primeiros movimentos de emergência não só econômica, mas como recorte geográfico e político nesta década, não só por ter sido pronunciada no Parlamento brasileiro, mas também em função do surgimento da ideia de criação de uma unidade administrativa e política, a saber: a "Província Centro Amazônica", proposta na obra Memorial Orgânico, escrita por Francisco Adolfo de Varnhagen, em 1850, uma contribuição do autor ao Império com vistas à organização política e administrativa do país ${ }^{33}$. A emergência não quer dizer consolidação, visto que a ampliação do uso do termo Amazônia para designar a região viria nas décadas vindouras. ${ }^{34}$

Explanado acerca dos aspectos econômicos contribuintes para a regionalidade em torno da região amazônica, deste ponto propomos encaminhar a discussão sobre a transformação das questões provinciais para os âmbitos regional e nacional partindo dos discursos dos representantes nortistas no Parlamento brasileiro, a exemplo de João Batista de Figueiredo Tenreiro Aranha, Herculano Ferreira Penna, Bernardo de Sousa Franco e Domingos Antônio Raiol, bem como Aureliano Cândido Tavares Bastos. Estejamos atentos no conjunto de pronunciamentos vindouros às preocupações com certa ampliação espacial do campo de argumentação parlamentar e com a condução dos temas desse espaço às esferas regional e nacional.

\footnotetext{
${ }^{31}$ COUTINHO, João Martins da Silva. Exportação da borracha pelas Províncias do Império do Brasil, dados do Ministério da Fazenda. (Manuscrito). 1p. Localizado em: Acervo João Martins da Silva Coutinho, Museu Paraense Emilio Goeldi. Belém/PA.

${ }^{32}$ WEINSTEIN, Barbara. op. cit. p.x. p.56.

${ }^{33}$ VARNHAGEN, Francisco Adolfo. Memorial Orgânico que a consideração das Assembleias geral e provinciais do Império, apresenta um brasileiro. Dado à luz por Um Amante do Brasil. Brasília: FUNAG, 2016.

${ }^{34}$ Antes de 1850, poucas e espaças referências eram feitas a essa parte do país a partir das palavras região amazônica ou Amazônia. Vejamos, por exemplo, que em 18 de junho 1865 o jornal Correio Mercantil (RJ) noticiava sobre a geografia do Mato Grosso, elencando que o território dessa província era confundido "[...] por largo tempo com o território imenso que designava então vagamente sob o nome de Amazonia".
} 
A questão da abertura do rio Amazonas à navegação internacional pode ser considerada a segunda grande batalha das elites econômicas e políticas desse espaço em relação à locomoção e ao transporte, levando em conta que a primeira peleja foi pela implantação da navegação a vapor, visto que desde 14 de julho de 1826, com a chegada da embarcação a vapor Amazonas ao porto do Pará, advinda dos Estados Unidos, as discussões sobre o assunto ganharam notoriedade diante da classe política paraense. Neste mesmo ano, por exemplo, após ouvir a classe comercial e os proprietários, o Governo do Pará recusou uma iniciativa estimulada pelo escritório de negócios do Brasil nos EUA em relação à concessão da primazia da navegação a vapor internacional na região aos americanos, mediante a alegação de que os últimos concentrariam o comércio e prejudicariam a classe comercial às margens do Amazonas. Em 1829, o tema da navegação a vapor reapareceu com a tentativa de criação da "Sociedade Promotora da Agricultura, Colonização, Construção de Embarcações, Comissões, Indústria Paraense”, pelo comerciante Joaquim José de Siqueira, mas o projeto não conseguiu apoio unânime na Assembleia Provincial. Durante o Primeiro Império e o Período Regencial, conforme Arthur Reis, a situação quanto ao tema era seguinte:

Faltava capital organizado, faltava coragem para cria-lo. Contra o estrangeiro
havia sempre uma onda de desconfiança. A nacionalidade estava nas suas
origens, a braços com as dificuldades da ordem interna, da pacificação dos
espíritos. Não seria perigo ir buscar lá fora o interesse, que podia esconder,
disfarçar intuitos, vontades imperialistas? ${ }^{35}$

Em 1848, o então Deputado paraense João Batista de Figueiredo Tenreiro Aranha conseguiu aprovar na Câmara dos Deputados três emendas ao Orçamento do Governo, sendo a principal: o emprego de dois barcos a vapor para a navegação do rio Amazonas e seus afluentes, sendo estes mesmos barcos utilizados para serviços de correios, transportes e "rebocagem". Para aprovar esse último ponto, Tenreiro Aranha argumentou "a necessidade de proteger a navegação do Amazonas, e lembra que é incontestável ser exclusivo dos nacionais o direito de navegação pelos nossos rios e costas". ${ }^{36}$ Assim, observa-se a condução do tema no âmbito nacional. Na mesma ocasião da aprovação das emendas do Deputado Tenreiro Aranha, o também Deputado paraense na Câmara dos Deputados Herculano Ferreira Penna solicitava a

\footnotetext{
${ }^{35}$ REIS, Arthur Cezar Ferreira. Panorama Econômico - Financeiro do Segundo Reinado: a navegação fluvial, especialmente a do Amazonas. Publicação do Instituto Histórico e Geográfico Brasileiro. Rio de Janeiro: Imprensa Nacional, 1942.
}

${ }^{36}$ Annaes do Parlamento Brasileiro. Sessão de 11 de agosto de 1848. p. 202. 
aprovação de uma emenda para a construção de um farol no litoral do Pará, em Atalaia, sob o argumento de que seria "uma obra, sem dúvidas, da mais urgente necessidade que se conhece no Brasil, e cuja a falta já tem causado e continuará a ser causa da perda de muitas embarcações". Mais uma vez, reaparece o discurso das necessidades paraenses apresentadas como nacionais.

Ainda em relação ao Deputado João Batista de Figueiredo Tenreiro Aranha, devemos lembrar que ele já esboçava em 1850 certa distinção entre o que era a província do Pará e a região amazônica, pois nos Anais do Parlamento brasileiro praticamente foi o primeiro político a utilizar a nomenclatura Amazônia, quando na sessão de 14 de fevereiro de 1850, ao polemizar com outro parlamentar sobre o orçamento das despesas do Ministério do Interior, Tenreiro Aranha acabou por tratar do tema educação mencionando a catequese dos índios do Pará que, na ocasião, foram considerados aptos para o trabalho e a navegação, elencando ainda: "Se eu já não tivesse tomado tanto tempo a casa, diria o nome de cento e tantas tribos das mais conhecidas que habitam lá na região Amazonica". ${ }^{37}$ A evidência ao termo Amazônia pode se rastreada por meio dos interesses do parlamentar, considerando que sua intenção era tratar sobre os temas da agricultura, comércio e navegação não só do Pará, mas da região, citando em sua fala o Alto Amazonas (Rio Negro). Deve-se atentar que o parlamentar já havia feito indicativo em 1849 para que se procedesse a elevação do Rio Negro à condição de Província da qual viria a ser o primeiro Presidente, o que permite aventar que a ideia de Amazônia em Tenreiro Aranha tenha emergido como uma visão política do espaço para além da ideia de Pará.

Em 1852, Tenreiro Aranha assumiu a Presidência da província do Amazonas, ao passo que seu substituto e suplemente no Parlamento brasileiro continuou a debater a questão da navegação a vapor como problema regional e nacional. Tratava-se de Ambrósio Leitão da Cunha, paraense que também foi Senador pelo Amazonas entre 1870 e 1889. Leitão Cunha assumiu o cargo de Deputado no momento em que se acentuava a diferenciação regional do Brasil entre Norte e Sul como espaços distintos e em disputa política, situação que pode ser refletida por intermédio do pronunciamento do Deputado Pernambucano Francisco de Paula Batista. Na sessão de 28 de junho de 1852, ele criticava a política de recrutamento do Império que, na visão do Deputado, prejudicava as províncias do Norte por retirar mais homens dessa área do país em detrimento das províncias do Sul, deixando a primeira com baixa mão

${ }^{37}$ Annaes do Parlamento Brasileiro. Sessão de 14 de fevereiro de 1850. p. 553. 
de obra, em um contexto do fim do tráfico negreiro, da queda dos preços do açúcar e da valorização do café no Sul. ${ }^{38}$

A ativa navegação a vapor veio com o Decreto imperial de agosto de 1852, quando efetivamente Irineu Evangelista de Souza (Barão de Mauá) teve a concessão dos privilégios da navegação no rio Amazonas com a criação da Companhia do Amazonas. Desde 1854, então, assumiu o compromisso de operacionalizar também um plano de colonização na região, especialmente fundando colônias estrangeiras. As tentativas das duas colônias com a vinda de portugueses e chineses não prosperou. A Companhia de Navegação do Amazonas não conseguiu atender toda a região e, com isso, foi gerado um sentimento de que o empreendimento nacional não atingia os objetivos requeridos pela região com uma economia extrativista crescente e uma demanda por colonização e agricultura.

No ponto acima, cabe mencionar que os políticos paraenses buscavam, ao mesmo tempo, fazer com que as demandas provinciais figurassem como questões regionais e nacionais, isto é, problemas que a Nação precisaria resolver, mas também procediam inúmeros discursos sobre a opulência da terra natal com promessas de desenvolvimento. Assim, postulavam que os "[...] Vales do Amazonas sabem quanta riqueza se oferece ali a atividade e quanta é a facilidade com que se pode obter por dia uma renda ao mais elevado salário [...]". Um espaço tido como possuidor de uma [...] natureza virgem, que tantos germes de riqueza prodigaliza ao homem". ${ }^{39}$ Nesse cenário, agentes externos viam justamente o contrário em relação às vantagens da natureza amazônica, como Irineu Evangelista (Mauá). Ele que, em 1857, escrevia sobre a colonização no Relatório da Companhia de Navegação do Amazonas que "a própria riqueza das magnificas regiões amazônicas é um óbice, por assim dizer, insuperável a realização de núcleos coloniais". ${ }^{40}$ Logo, percebemos que concorriam diferentes visões acerca das ideias de natureza e riqueza, não mais da província, porém de um espaço amplo: a região.

Todo esse debate da década de 1850 sobre a navegação do rio Amazonas em âmbito nacional não foi trivial, visto ter sido uma década marcada pela chamada cobiça internacional. Magnoli considera que "a partir de meados do século, o esboço de uma estratégia sul-americana afirmativa dos Estados Unidos foi percebido pelo Império como uma fonte de novas ameaças para o

\footnotetext{
${ }^{38}$ Annaes do Parlamento Brasileiro. Sessão de 28 de junho de 1852. p. 448.

${ }^{39}$ RAIOL. Abertura do Amazonas. op. cit; p. x. 1867. p.106.

${ }^{40}$ Relatório da Companhia de Navegação do Amazonas: In. RAIOL, Domingos Antônio. op. cit; p. x.1867.p. 107.
} 
domínio brasileiro sobre o espaço articulado pelo grande rio". ${ }^{41}$ Essa situação do interesse americano na bacia amazônica foi mais um capítulo do interesse internacional por essa parte do Brasil, visto o histórico de pretensões francesas e britânicas na região.

Em meados do século XIX, com o contexto de expansionismo americano direcionado para América Central e o Caribe, o tenente da marinha estadunidense Matthew Maury desencadeou uma campanha em prol da abertura do rio Amazonas à navegação internacional, um projeto oficialmente relacionado à comunicação e ao comércio, mas que possuía outros objetivos, como a colonização agrícola das margens do Amazonas com o plantio de algodão e borracha. Os problemas internos americanos relacionados com a escravidão e a Guerra da Secessão sobrepujaram a discussão sobre o Vale amazônico e a questão arrefeceu. ${ }^{42}$

O desfecho da discussão da abertura do rio Amazonas veio no contexto da Guerra do Paraguai. Na década de 1860, o Império brasileiro estabeleceu a livre navegação no Amazonas por intermédio do Decreto 3749 de 7 de dezembro de 1866, visto que duas situações nessa matéria contrastavam no cenário brasileiro da época: a situação da bacia Platina e da bacia amazônica. Sendo assim, o Brasil argumentava a respeito da necessidade da livre navegação no rio da Prata contra a posição do Paraguai, o que tornava insustentável a permanência do fechamento do rio Amazonas, bem como gerava uma situação contraditória. Em função da guerra também passavam a ser tênues as relações diplomáticas com potências como Inglaterra e os Estados Unidos, ambas com interesses na abertura da navegação na fronteira norte do Brasil.

O Decreto de 7 de dezembro de 1866 também foi fruto do intenso debate travado no Parlamento brasileiro, com a apresentação de projetos no âmbito legislativo e o debate extra Parlamento em folhetos, jornais e livros. No Parlamento, em 1864, o autor do projeto de abertura do rio Amazonas, o paraense e liberal Tito Franco de Almeida, aliava os princípios liberais e a ideia de que a referida demanda era de âmbito nacional e internacional. Para justificar o projeto, argumentava em prol da "completa liberdade de comércio e navegação do Amazonas", visto a grande influência na prosperidade do país e das províncias ribeirinhas, leia-se os países fronteiriços.$^{43} \mathrm{~A}$ década de 1860

\footnotetext{
${ }^{41}$ MAGNOLI, Demétrio. O Corpo da Pátria. Imaginação geográfica e política externa no Brasil. São Paulo: Editora da Unesp/ Editora Moderna, 1997, p. 175.

${ }^{42}$ Ibidem.

${ }^{43}$ Annaes do Parlamento Brasileiro, sessão de 13 de fevereiro de 1864. In: RAIOL, Domingos Antônio. Abertura do Amazonas. op. cit; p. x. 1867. p.7.
} 
é um período bastante sintomático para o aprofundamento das discussões no país. Foi o momento no qual os liberais marcaram novamente posição na cena e no debate político, visto que o Partido Liberal voltou a ocupar cargos no Governo Central desde 1853 com a chamada política de conciliação e, nos anos sessenta, conseguiu agitar a paisagem política nacional mediante o discurso, a propaganda e no afinamento das suas pautas com o cenário mundial. ${ }^{44}$

Um dos atores mais conhecidos dessa geração de liberais da década de 1860 foi Aureliano Cândido Tavares Bastos, deputado nortista, natural de Alagoas e que se destacou no Parlamento brasileiro pela defesa das teses liberais, especialmente pela tese da descentralização política. Tavares Bastos escreveu Cartas ao Solitário (1862) e o Vale do Amazonas (1866) nos anos sessenta do século XIX e ainda A Província (1870). No tocante ao que interessa para esse texto, cabe citar, em linhas gerais, a participação de Tavares Bastos na questão sobre a abertura do rio Amazonas à navegação internacional. Tavares Bastos foi um dos políticos liberais nortistas externos ao Vale amazônico mais interessados e ligados às discussões provinciais, especialmente sobre temas amazônicos. Ele esteve pessoalmente na região amazônica em 1865, tempos em que o recorte regional Amazônia ainda estava em fase de elaboração. Por isso, em suas obras alguns termos são utilizados para designar a região, como Províncias Equatoriais, Vale do Amazonas, região amazônica e Amazônia.

O Deputado alagoano e nortista, em discurso na Câmara dos Deputados, no ano de 1862, tratou sobre o projeto de navegação a vapor e a livre navegação, reverberou sua inquietação com a questão advogando a imediata abertura do rio em nome da civilização, do comércio internacional e da resolução de questões relacionadas às fronteiras do Norte do país, elencando ainda que:

"Abrir o amazonas é marcar a data mais brilhante nos anais do nosso progresso;
abrir o Amazonas é soltar os diques das aspirações legítimas e repelir os
incitamentos da anarquia provocados pela injustiça; abrir o Amazonas é dar
a prova mais estrondosa da fecundidade de nossas ideias e da grandeza de
nossas vistas.

Tavares Bastos, ao passo que elevou a questão da navegação ao nível nacional, quando postulou que a civilização chegará ao Brasil pela entrada dos Estados Unidos na região amazônica, também reverberou artifícios

${ }^{44}$ CARVALHO, José Murilo de. Clamar e agitar sempre: os radicais da década de 1860. Rio de Janeiro: Topbooks, 2018.

${ }^{45}$ BASTOS, Aureliano Cândido Tavares. Observações ao projeto sobre a navegação a vapor para os Estados Unidos e a abertura do Amazonas, realizadas na sessão de 8 de julho de 1862, da Câmara dos Deputados. In: Cartas ao Solitário. $4^{a}$ ed. São Paulo: Editora Nacional; Brasília, INL, 1975 (Brasiliana), p. 288. 
discursivos da elite política paraense e amazonense em seu discurso, a saber: a desconstrução da ideia de terra deserta e improdutiva, além de apontar na direção da ideia de terra opulenta, considerando que "Se a região amazônica é o que há na terra de mais potentoso e de mais incrível, como se concebe que deva permanecer inculta e inútil?". ${ }^{46}$ A argumentação do autor se alinhava também as elites amazônicas quando defendia a navegação estrangeira para a introdução de braços na região: "Para o Vale do Amazonas, para as nossas belas províncias do Equador, o comércio livre nos rios é como o ar para os pulmões. Não podem dispensá-los, porque não têm abundancia de braços: e só navio estrangeiro introduzirá braços". ${ }^{47}$

Tavares Bastos por meio da escrita exerceu fortemente o combate ao centralismo do Governo e a defesa pelos temas liberais que militava, em outro aspecto se somou à postura das elites políticas amazônicas: elevar temas regionais ao nível nacional como foi o próprio caso da livre navegação no rio Amazonas, argumentando que:

Ver-se-à do quadro ligeiro de sua situação que o que mais reclama a medida do livre comércio do Amazonas, é próprio interesse do Brasil, e que, pois, essa medida deve ser decretada como coisa sua, como ato da sua soberania, necessário ao bem-estar dos povos e ao desenvolvimento da riqueza pública. ${ }^{48}$

É preciso considerar que os motivos que levaram Tavares Bastos a se interessar pela questão do rio Amazonas não eram os mesmos da elite política amazônica. Um dos motivos que levaram o Deputado alagoano a se aproximar do Vale do Amazonas e defender os interesses dessa parte do país liga-se à sua trajetória política e de pensamento intelectual de crítica ao Centro, ou seja, ao Governo Central, uma vez que essa postura lhe conduzia às margens. Logo, a região amazônica era ambiente perfeito para o desenvolvimento de suas críticas ao Império e o laboratório de experimentação de seu pensamento descentralizador, o que fez se emanar com os liberais do Pará.

Outro parlamentar pertencente ao quadro do Partido Liberal, desta feita natural e representante do Pará na Câmara dos Deputados, foi Domingos Antônio Raiol. ${ }^{49}$ Ele assumiu postura em defesa das grandes questões de sua

\footnotetext{
${ }^{46}$ Ibidem, p. x. p. 207.

${ }^{47}$ Ibidem, p. x. p. 221.

${ }^{48}$ TAVARES BASTOS, A. C. O Vale do Amazonas: a livre navegação do Amazonas, Estatística, produção, comércio, questões fiscais do vale do Amazonas. 3. ed. São Paulo: Ed. Nacional, Brasília, INL, 1975.

${ }^{49}$ Domingos Antônio Raiol foi um intelectual com formação jurídica e atuação política no Norte brasileiro no século XIX, especialmente no período do Segundo Reinado. Natural de Vigia, no Grão-Pará (1830-1912), estudou Direito em Olinda/PE. Desde a década de 1860, marcou sua atuação na política nacional sendo
} 
terra natal no início da década de 1860, como a abertura do Rio Amazonas e a imigração. Domingos Raiol foi o organizador do documento Abertura do Amazonas: Extratos dos debates no Parlamento brasileiro acerca do projeto de lei sobre a abertura do Rio Amazonas à navegação e ao comércio do mundo (1867), uma coletânea reunindo vários debates e pronunciamentos realizados no Parlamento brasileiro sobre a questão da abertura do rio Amazonas à navegação internacional. Um documento com uma introdução balizada pelo notório alinhamento aos preceitos do liberalismo, pois considerava que "o princípio de liberdade é hoje o elemento vital das sociedades modernas" ${ }^{50}$, e ainda com a notável pretensão de evidenciar que as questões amazônicas eram promissoras também para o Brasil, pois julgava que "o Brasil não poderia ser indiferente ao brado dos operários do progresso. A liberdade de navegação e comércio do Amazonas eram um alimento indispensável para o seu florescimento e futura grandeza". ${ }^{51}$

Em concomitância com a apresentação das complexas questões que retardavam o progresso do Pará e do Amazonas por parte dos parlamentares, também eram aludidos os benefícios que as mesmas questões trariam, caso fossem resolvidas. Na introdução do documento de 1867 (Coletânea de discursos parlamentares), possivelmente apresentada pelo próprio Raiol, enfatizava-se que:

A questão da abertura do Amazonas à navegação e o comércio do mundo é uma das mais importantes que se tem suscitado neste século; é um precioso legado transmitido às gerações vindouras, há de seguramente de engrandecer o Império e as Repúblicas vizinhas". ${ }^{52}$

Foi muito presente nos pronunciamentos no Parlamento a importância da abertura do rio Amazonas para as relações com os países do capitalismo mundial e latino-americanos (ribeirinhos) que estavam na zona de fronteira amazônica.

A Coletânea em tela possibilita aferirmos o debate da demanda por inserção do Pará por meio da ampliação espacial para região amazônica no processo de construção do Estado Nacional com as reivindicações parlamentares. Os discursos advindos dos representantes amazônicos denotam que eles

eleito deputado para a Câmara dos Deputados do Império. Além disso, por meio de indicação imperial, foi presidente das províncias de Alagoas (1882), Ceará (1882) e São Paulo (1883). Em 1883 recebeu o título de Barão de Guajará.

${ }^{50}$ RAIOL. Abertura do Amazonas. op. cit; p. x.1867, parte I.

${ }^{51}$ Ibidem.

${ }^{52}$ Ibidem, p. X., p. 7 
falavam de um espaço além da noção provincial, suas posturas pautaram-se na região, uma área diferenciada no conjunto geográfico brasileiro. Portanto, ao levar em conta que o conceito de região, grosso modo, faz menção à noção de diferenciação de espaço, como explicita Roberto Correa, ${ }^{53}$ aventamos que, no caso de Raiol, na década de 1860, já existiam traços de certa consciência regional - situação que pode ser estendida a outros agentes políticos da época -, oscilando entre os seguintes termos: Pará, Vale do Amazonas, Vale amazônico e a região amazônica, utilizados como sinônimos, o que demonstra que esse era um período de transição da postura política provincial para a regional e que a noção de Amazônia ainda não estava cristalizada e não formulada completamente.

O trato diferenciado entre a província (Pará) e a região ou a oscilação entre o uso dos termos fica patente na medida em que são examinados os pronunciamentos de Domingos Antônio Raiol, como podemos observar em um trecho do seu pronunciamento sobre o papel da Assembleia Provincial na questão imigratória, elencando que "as assembleias provinciais podem promover a imigração. A Assembleia do Pará deveria tomar o maior empenho possível neste serviço indispensável às regiões amazônicas" ${ }^{54}$ Nesse trecho, 0 parlamentar separa a Assembleia Provincial e os fins de sua atuação para as regiões amazônicas. Além do que, o chamamento para a deputação provincial agir com relação à imigração revela algo maior, notadamente a ideia de superação das posturas e pensamentos provinciais para se unir com vistas ao desenvolvimento de um espaço mais vasto: a(s) região(ões).

Uma das possibilidades de influência para a emergência da nomenclatura amazônica perante os representantes da região possui relação com a própria imagem construída sobre esse espaço, como já mencionado acima, sobretudo a partir de 1850 com os ganhos da borracha, momento em que a região passou a nutrir a ideia de superação da imagem atrasada que pesava sobre si. As denominações referentes à região amazônica e à Amazônia dizem respeito a um processo de substituição do imaginário sobre o espaço, sabendo que o conjunto de ideias e imagens de representação coletiva de um lugar atrasado, de natureza impenetrável e de clima hostil foi sendo combatido visando uma representação atrelada a uma rica e exuberante natureza, um clima igual a outros do mundo, além da ideia de terra opulenta, que reunia as mais variadas condições para o progresso e a civilização.

\footnotetext{
${ }^{53}$ CORRÊA, Roberto Lobato. Região e Organização espacial. 7. ed. São Paulo: Editora Ática, 2003. Série Princípios. ${ }^{54}$ RAIOL. Abertura do Amazonas. op. cit; p. x. 1867. p. 113.
} 
A transformação do imaginário com a mudança do nome que se atribui ao espaço reflete também um processo de construção da identidade regional. Leoni e Carnicer, por exemplo, identificaram a importância da denominação Nordeste para a constituição de um espaço regional argentino no século XX. ${ }^{55}$ Margarita Hernandez, ao refletir sobre a ligação entre o nome e a região, considera que:

No caso das regiões, a nomenclatura é uma construção social, articulada sobre a existência de uma diferença com respeito a outras regiões, na qual se valorizam o aspecto particular, o aspecto próprio dela, a sua cultura, as suas tradições, os seus habitantes e os elementos geográficos. ${ }^{56}$

Os representantes amazônicos trabalharam justamente para reverter a imagem de atraso da região e atrair a imigração, a exemplo de um pronunciamento sem identificação, mas com grandes possibilidades de ter sido realizado por Domingos Raiol, quando tratou das causas que dificultavam a imigração estrangeira para o Norte do Brasil e, entre essas, o caso da imagem no estrangeiro, pois "os viajantes estrangeiros que visitam nossas plagas são de ordinário prodigo nas censuras e apreciações que certo não merecemos". ${ }^{57}$ Ainda com relação aos viajantes, o autor ressalta que:

As asserções grosseiras de Emilio Carrey passariam também sem o menor protesto, se Silva Vieira traduzindo em Portugal Os Mulatos do Marajó e os Revoltosos do Pará na contradissesse ao autor de tais escritos num ou noutro ponto que lhe pareceu por demais exagerado, ficando, entretanto, a maior parte das invenções sem reparos sequer por parte dos nossos agentes no reino de Portugal e Paris. ${ }^{58}$

A queixa contra os viajantes e naturalistas estrangeiros que produziam imagens tidas como distorcidas do Norte e do próprio Brasil não era apenas das elites amazônicas. Desde a década de 1850, vários membros do Instituto Histórico e Geográfico Brasileiro faziam várias críticas aos viajantes internacionais pela forma como representavam o Brasil na Europa.

\footnotetext{
${ }^{55}$ LEONI, María Silvia; CARNICER, María del Mar Solís. Los procesos de regionalización en el Nordeste argentino en las décadas de 1960 y 70: el aporte de las Ciencias Sociales. Revista TEL, Irati, v. 9, n.1, p. 3243,jan. /jun. 2018-ISSN 2177-6644.

${ }^{56}$ HERNÁNDEZ, Margarita Silva. O nome de Centroamérica e a invenção da identidade regional. In: CHIARAMONTE, José Carlos; MARICHAL, Carlos; GRANADOS Aimer. Criar a Nação: história dos nomes dos países da América Latina. São Paulo: Hucitec, 2017. p. 220.

${ }^{57}$ RAIOL. Abertura do Amazonas. op. cit; p. x. 1867. p.111.

${ }^{58}$ RAIOL. Abertura do Amazonas. op. cit; p. x.1867. p. 112
} 
Um dos homens de ciência que agradou parte das elites políticas amazônicas foi Louis Agassiz. Quando veio dos Estados Unidos com sua esposa Elizabeth, Agassiz liderou uma expedição científica ao Brasil entre 1865 e 1866. Desde então, suas palestras e publicações foram defendidas por representantes amazônicos no Parlamento. Na década de 1860, ainda, as reflexões do referido viajante foram utilizadas para defender a região da histórica acusação de que o seu clima era inapropriado à vivência de povos europeus, por isso, no mesmo pronunciamento em tela, o autor dizia que: "Fale por nós um homem que, não nascido no Amazonas, não poderá ser considerado exagerado [...]", ${ }^{59}$ continuando, desta feita, expôs a própria fala de Agassiz sobre o clima: "A uniformidade do clima no Vale amazônico, a pouca intensidade das variações termométricas influem também sobre o caráter de seus habitantes. Todavia, o clima uniforme e úmido, é mui salubre". ${ }^{60} \mathrm{Com}$ Agassiz, então, foi informado no Parlamento brasileiro que "está verificado hoje que o clima das regiões amazônicas não é nem ardente, nem insalubre como dantes muita gente acreditava". ${ }^{61}$

Pelo menos no discurso parlamentar da década de 1860, Agassiz foi tido como alguém que provocou boa imagem do Vale amazônico na Europa, embora esse mesmo viajante também tenha sido considerado como produtor de uma representação negativa da região com a compreensão de que esse espaço era habitado por "raças inferiores", chegando a criticar o processo de miscigenação e defendendo a imigração de povos "superiores". ${ }^{62}$

$\mathrm{Na}$ rede de circulação internacional junto às elites nortistas, ele pode ser considerado um dos vetores para a mudança do nome referente ao espaço às margens do rio Amazonas, por várias vezes esse zoólogo suíço e radicado nos Estados Unidos fez menção à região amazônica em suas palestras e textos, ${ }^{63}$ como o relato de viagem intitulado de Viagem ao Brasil (1867). Além do que, a posição de Agassiz no intercâmbio com homens de ciência e políticos brasileiros não deve ser esquecida quanto à recepção e reprodução das expressões. É oportuno lembrar que um dos homens que auxiliou esse viajante

\footnotetext{
${ }^{59}$ Ibidem, p. x. p. 100

${ }^{60}$ Idem, p. x.

${ }^{61}$ Ibidem, p. x. p. 103.

${ }^{62}$ Sobre a viagem de Louis e Elizabeth Agassiz, recomenda-se a leitura do texto: KURY, Lorelai B. A sereia amazônica dos Agassiz: zoologia e racismo na Viagem ao Brasil. Revista Brasileira de História. São Paulo, v. 21, no 41, p. 157-172. 2001.

${ }^{63}$ Destaca-se a palestra ministrada em Belém do Pará, em 2 de março de 1866. Sobre o assunto ver: Formação do Vale do Amazonas. Jornal do Commércio. Rio de Janeiro, 1866. Disponível em: http://bndigital.bn.gov. $\mathrm{br} /$ hemeroteca-digital/
} 
no Norte do Brasil durante a sua expedição foi João Martins da Silva Coutinho, engenheiro com forte representação no Império. Ele que já utilizava antes da vinda de Agassiz vocábulos mencionados pelo viajante a respeito da região, como bacia amazônica, em $1863 .{ }^{64}$ Nesse circuito, é imperioso assinalar que Agassiz encontrou, durante a sua expedição ao Norte, Tavares Bastos que, possua vez, também se inclinou a falar em região amazônica.

Ainda sobre a circulação e intercâmbios, cabe salientar que a elite política amazônica interessada no projeto de abertura do rio Amazonas à navegação internacional estava ciente do momento histórico vivido no mundo, marcado pelas ideias liberais. Salienta-se que entre 1848 e 1870, tal como fora proferido por Hobsbawm, "foi o período no qual o mundo se tornou capitalista e uma minoria significativa de países "desenvolvidos" transformou-se em economias industriais". ${ }^{5}$ Uma época marcada por "[...] uma série de "tratados de Livre comércio" que cortaram substancialmente as barreiras de tarifas entre as nações industriais líderes na década de 1860", ${ }^{66}$ quando a medida material do momento era a força a vapor associada ao ferro e ao carvão. Sem possuir parques industriais, tanto o Brasil quanto o Amazonas, aos olhos liberais, entrariam no circuito pautado pelo comércio de produtos primários e alimentos, como era o desejo da Inglaterra em relação aos países subdesenvolvidos.

Observamos que a ideia era transformar a região em rota do capitalismo mundial, tendo como foco atrair o comércio do Pacífico, sendo “[...] necessário fazer dos portos amazônicos o empório das repúblicas banhadas pelo grande rio, melhorando desde já as condições fiscais do país [...]" ${ }^{67}$ Assim, postulava-se uma região que receberia "braços", capitais, experiências e indústrias.

\section{Considerações Finais}

A qualidade de Estado separado do Brasil e a distância geográfica que possuía em relação aos centros de poder no período colonial, respectivamente a Bahia e a Corte no Rio de Janeiro, permitiram ao Grão-Pará estabelecer dinâmicas próprias de funcionamento. No entanto, também criou certo distanciamento, situação que foi acentuada com o não alinhamento de primeira hora com o projeto de independência iniciado no Sul e com a Cabanagem. Assim, esse conjunto de fatores acabou gerando um movimento, por parte da

\footnotetext{
${ }^{64}$ Exploração do Rio Purus na região Norte. Jornal do Rio de Janeiro. Rio de Janeiro. 1863. Disponível em: http://bndigital.bn.gov.br/hemeroteca-digital/

${ }^{65}$ HOBSBAWM, Eric J. A Era do Capital 1848-1875. 21. ed. São Paulo: Paz e Terra, 2014. p. 60.

${ }^{66}$ Ibidem, p. x. p.70

${ }^{67}$ RAIOL. Abertura do Amazonas. op. cit; p. x.1867. p.115.
} 
classe política paraense, com a perspectiva de reverter a falta de atenção e o afastamento do Governo Central, além da busca por inserção nos quadros do poder nacional. Pode-se dizer que o discurso do abandono da Província foi um posicionamento voltado para demarcação do espaço e sua representação, o que, posteriormente, foi convertido conforme o chamamento das questões provinciais alçadas como de interesse regional e nacional.

Duas circunstâncias presentes no conjunto dos pronunciamentos dos parlamentares nortistas são importantes para compreensão do artigo proposto. Primeiro, embora também utilizassem o termo Pará, nota-se que após 1850 tendiam a falar para além do espaço paraense, com nítida vertente regional e a devida ênfase para o Vale e a região amazônica. Portanto, este artigo descortina o momento inicial do discurso regional na Amazônia, forjado na circulação de ideias e do intercâmbio de percepções sobre o espaço nortista às margens do rio Amazonas. Segundo, ao passo que discursavam em nome de uma área maior que a Província, os parlamentares buscavam concomitantemente elevar as questões complexas do âmbito provincial ao domínio regional e nacional, denotando a dupla tarefa de criar as condições de emergência da ideia da região amazônica e de inseri-la na Nação.

Esse processo de luta e posicionamento em prol da representação e poder para o espaço de origem, por parte dos agentes políticos nortistas, teve no período entre 1840 e 1867 os temas da navegação e da imigração como principais. Para tanto, cumpriam o papel de chamar a atenção para o espaço amazônico com base na condição dos problemas e, ao mesmo tempo, das promessas para o desenvolvimento regional e nacional.

Artigo recebido para publicação em 17/05/2020

Artigo aprovado para publicação em 03/09/2020 